氛的含量对肥效的影响有两种可能，一种是在原 来矿石中形成結晶完整的氟一灰石, 使不易被分 等; 另一种是在中性或铛碱性 反应的条件下，与 $\mathrm{C}_{23}\left(\mathrm{PO}_{4}\right)_{2}$ 結合, 向氛一群石方向轉化, 使原 来可 能被植物利用的磷源，又重新被周定。因此，不能簡 单地像一般所馀, 解量高低, 就意味着直接施用时肥 效的大小。从表 1 和表 2 可以看出，同台两磷矿含第

是最高，而其肥效却很显著。

在砂培中，各地磷矿粉的相对肥效次序是:

昆陽>圂台>四川>䈍义>海州;

田閶試驗时肥效的次序是:

風台 $>$ 昆陽 $>$ 四川>逢义>海州。

前者与表 1 楼㧼酸溶性 $\mathrm{P}_{2} \mathrm{O}_{5}$ 量完全一致，相关 情况可以圖 2 表示。因此橴䒸酸溶性 $\mathrm{P}_{2} \mathrm{O}_{5}$ 量可以作 为磷矿粉相对肥效的一个指标。后者与圖 1 的溶解曲 的陡度次序亦可算符合，所以对磷矿粉肥效亦有参 考的价做。贵州磷矿粉肥效与这两个指标不大相称， 这可能与此磁矿的結构有关。

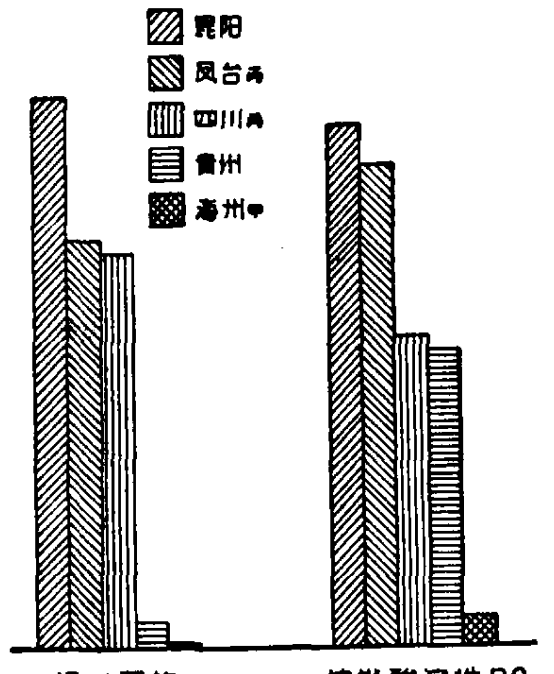

相对戋奴

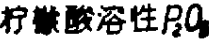

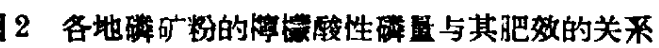

必須指出，風台磷矿粉在第四紀紅色粘土發育的 䉺饻上有一定肥效，但推广时必須注意环境条件。

蔣柏藩推建昌胡光鲁如坤 （中国科学院土瑟研究所） 1957 年 8 月 23 日

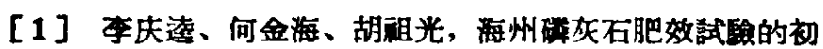
步报告，土暨学报，2，37-42（1952）。

[2] Thorpe's Dictionary of Applied Chemistry, 4th ed, vol. 2, p. 122.

[3] C. S. Piper, Soil and Plant Analysis, Interscience Publishers, p. 274.

\section{家基酸和蛋白垩对好气 性固氮菌固氮能力的影响}

关于某些含氮化合物对固氮菌固 氮力影响的問
題, 已䋑有不少的报导。早在 1931 年Fuller [1] 就指 出了酪氮酸、天門冬氮酸、谷䒺酸及蛋白腖等，有降 低以致抑制 Az. Chroococcum 的固氮力的事实。但 在 Greaves ${ }^{[2]}$ 的报导中，却又証实了酪氮酸、組姿

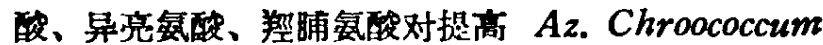
的周氛力特別有效。其后 Horner[3] 和 Wilsm[4]等, 又先后指出天門冬酫胺有降低闾氮力的現象。近年来 苏联科学家 Федров[5.6]在这方面进行了一系列的研 究。証实当培养液中存在少量的天門冬氨酸或谷氮酸

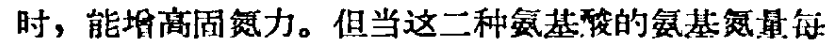

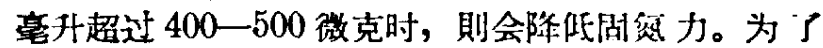

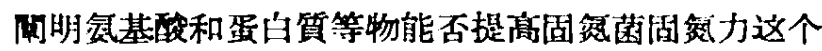

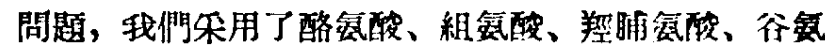
酸、天門冬醭胺、蛋白崃和白朊等进行了試驗。

供試菌株选用我空分得的好气性固氮菌中，風于 Az. Chroococcum, Az. Beijerinkii, Az. Vinelandii 三个不同固氮菌种，而具有不同固筧力的 8 个 菌株。用 Burk 氏培养基作为我們的基础唔养基。于 唔养基中分别加入不同濃度（每毫升含 $25,50,75,100$ 徽克)的氮基酸或蛋白質。用試管于 $25^{\circ} \mathrm{C}$ 静㯰培养。 25 天后分别測定总氮量和培养基中的殘柤量，从洏訫

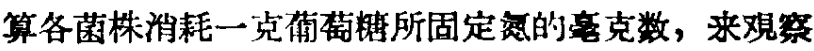
它們固䆦力的变化。

我們的試驗結果証明:

1.同一氮基酸或蛋白質的不同漕度，对同一菌株 的固氮力具有不同程度的影响, 各具有其最适的濒度。

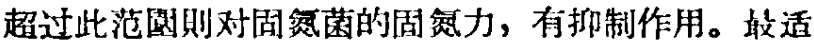
漶度的范園，一般在每毫升培养基含 25 至 75 微克之 間 (圖 1-3)。

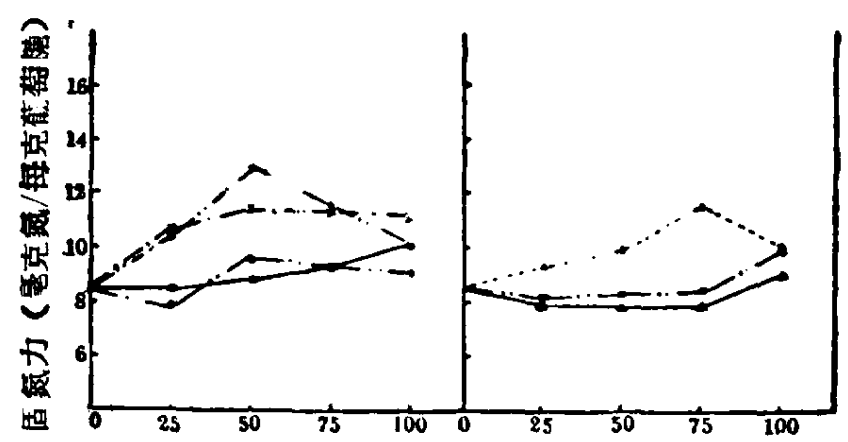

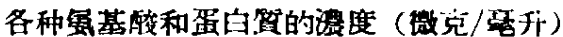

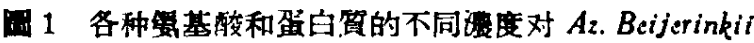
2 缶菌珠固氮力的影响。

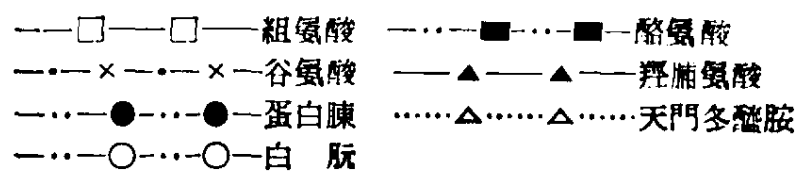

2. 同一氛基酸或蛋白筫对不同菌株的固筑力显示 不同的影响。这不但表現在对不同菌株闰氮力提高的 程度上的显著不闰，而其最适謴度美异也頗明显。如 
对 Az. Chroococcum 2 号, Az. Beijerinkii 3 号 Az. Vinelandii 265 号菌株, 蛋白脨的最适濃度, 分 別为 50 微克、 75 微克和 50 微克。固锱力分別提高 $52 \% 、 82 \%$ 和 $44 \%$ ；酪琙酸的最适濃度分品为 100 微 克、50 微克和 75 微克，固资力分别提高 $17 \% 、 9 \%$ 和 $46 \%$; 谷氮酸的最适濃度均为 50 微克, 固氮力分別提 高 $34 \% 、 74 \%$ 和 $34 \%$ (圖 4-6)。

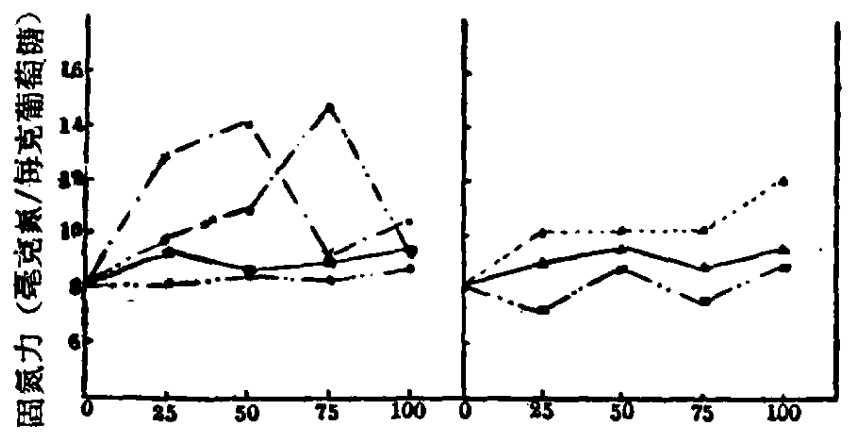

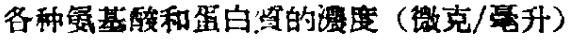

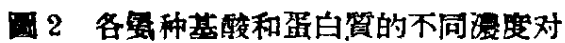
A2. Chroococcum 3 曷菌株固是力的 影响

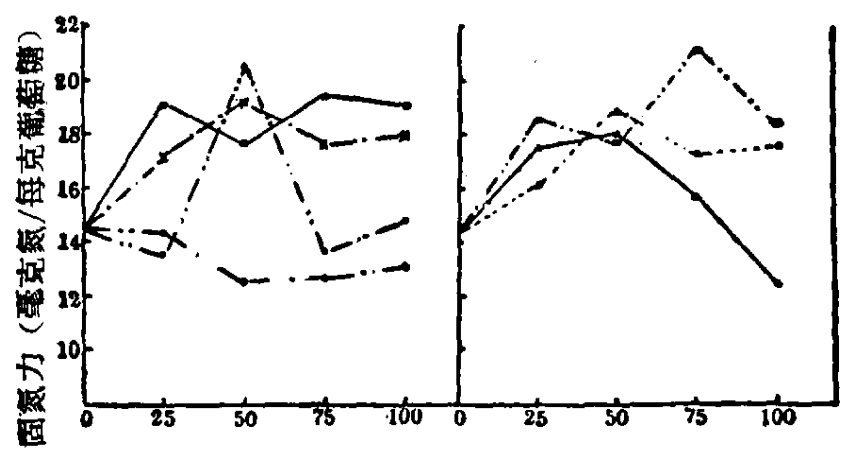

各种舅基酸和蛋白貿的惯度（微克/毫升）

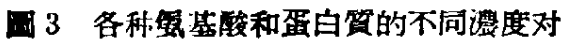
Az. Vinel andit 265 易菌株阁氮力的 影响

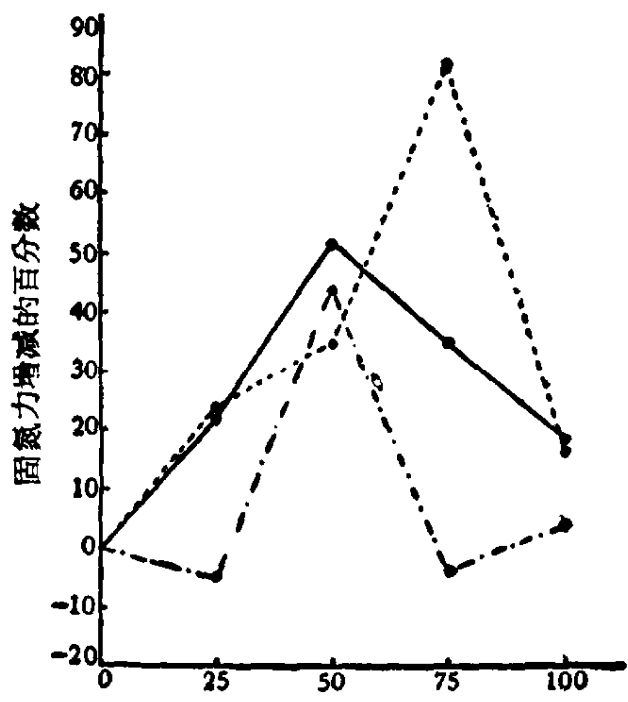

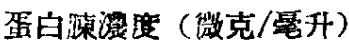

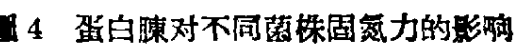

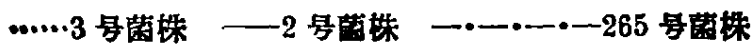

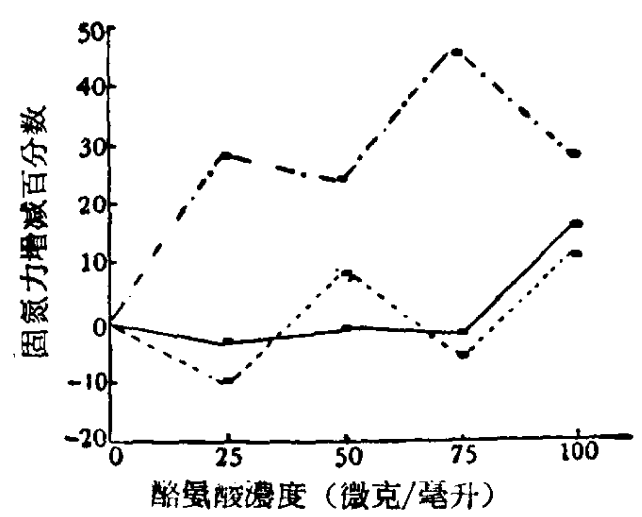

国 5 酪鲳酸对不同菌株固复力的影响

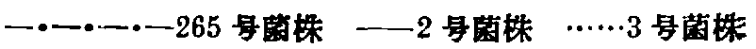

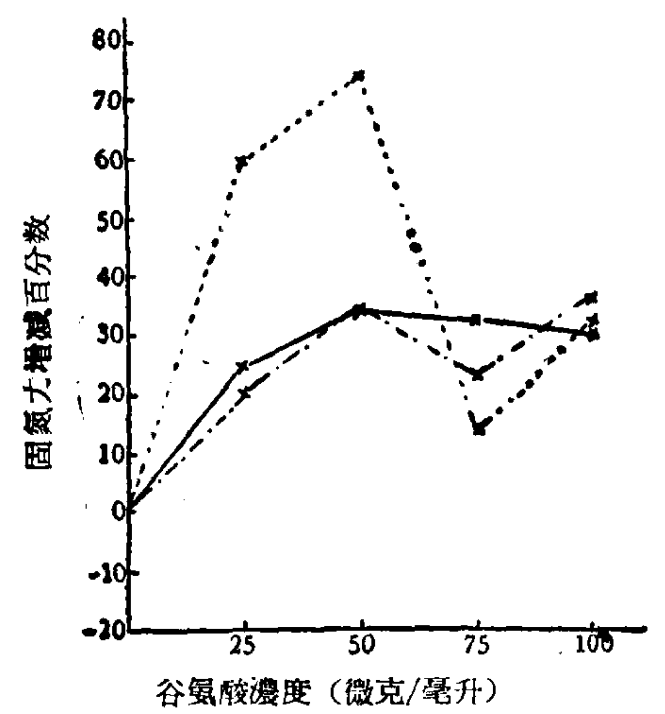

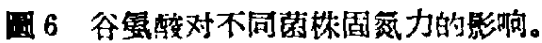

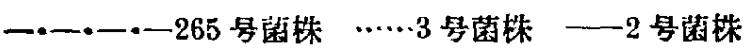

3. 不同氮基酸或蛋白質对同一菌株固氮力的影响 有显著的差异。个男心氮基酸对个別菌株显得特殊有效， 相反地某一些含氮化合物对提高固氮力就饪然無效, 谌至降低菌株的固氮力。如蛋白湅和天門冬醏胺, 对 提高 Az. Chroococcum 2 号菌株的固氮力比較有效, 而酪氛酸、援脯氮酸等則不显著。蛋白湅和谷氮酸对 提高 Az. Beijerinkii 3 号菌株的固氮力的效果較为 显著，而白朊、酪氮酸則較差。蛋白湅、酪氮酸等对 Az. Vinelandii 265 号菌株固资力显得有 效, 而白 朊則有降低其固氮力的作用。(圖 1-3)。

由我們初步的試驗結果, 可以看治在基础培养基 中添加适当量的适当氨基酸或蛋白腖, 可以显著地提 高需敂雕菌的固氮力。这給定向培育固氮力較高的 菌种，指出可能的叙徑。目前，我們正在上远試验所 得結果的基础上，选用对提高固嵫力有效的㑹基酸和 蛋白腖濃度, 来进行菌株的連續移代培养。冀以改变 固氮菌原有的性能, 而获得稳定的固氮力更禀的有效 菌株，以为农業增产服务。同时，投进一步探索菌株 的某些生理特征, 为闻明固氮力提高的队在因素提供. 
張宪武韓静淑 单慰會

郑鴻元 柴 明

(中国科学院林業土虽研究所)

1957 年 8 月 12 日

[1] J. E. Fuller and L. F. Rettger, Soil Science, 31, 219-234,(1931).

[2] J. E. Greaves, L. Jones and A. Anderson, Soil science, 49, 9-19(1940).

[ 3 ] C.K. Horner and F. E. Allison, J. Bact., 47, 1-14 (1944).

[4] P. W. Wilson, J. F. Hull and R. H. Burris, Proco Natl. Acad. Sci. U. S., 29, 289(1943).

[5] М. В. Фөцров, Микробиология, Т. 17, Стр. 425 (1948).

[6] М. В. Федров, Биологическая Фиксация Азота Атмосферы, Сөльхозгиз, Москва, 1952.

\section{棉花黄萎病發生及 潛育期研究简报}

棉花黃萎病在我国东北、华北、西北等地重点棉 区早已先后發生，近几年来抹且逐年寡延加重。关于 此病的分布被生和为害情况，各地区有关单位亦會进 行調查，所得結果大致相同。但是在对于苗期是否發 病, 还存在着不同看法, 文献中也說法紛云。我們會 椫进行了試驗（于1955 年 5 月 18 日播种), 結果如下 表:

\begin{tabular}{|c|c|c|c|c|c|c|c|}
\hline \multirow[b]{2}{*}{ 处 } & \multicolumn{2}{|c|}{ 接 } & \multicolumn{2}{|c|}{ 球 } & 房 & \multicolumn{2}{|l|}{$(\%)$} \\
\hline & 月 & 日 & \begin{tabular}{|l|l|} 
目 & 日 \\
\end{tabular} & $\left|\frac{1}{7}\right| \frac{6}{4}$ & $\left|\frac{9}{7}\right| \frac{\theta}{7} \mid$ & \begin{tabular}{|l|l|} 
日 & 至 \\
7 & 23 \\
\end{tabular} & \begin{tabular}{|l|l|} 
& $\frac{\text { 日 }}{7}$ \\
\end{tabular} \\
\hline 播种时土譔挠种 & & 18 & $\ldots$ & 一 & 0.90 & 0.90 & 2.70 \\
\hline 、 $2-3$ 片具叶土瀷接种 & & 14 & - & - & - & 0.92 & 3.10 \\
\hline 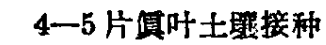 & & 23 & - & - & - & - & 0.97 \\
\hline 6-7片笑叶土琵接种 & 7 & 4 & - & - & - & - & 1.01 \\
\hline 2-3 片真叶案刺接种 & 6 & 14 & 51.49 & 59.41 & 61.39 & 49.50 & 50.50 \\
\hline 4-5 片面叶综刺接种 & & 23 & 一 & $\longrightarrow$ & 35.45 & 40.91 & 41.82 \\
\hline 6-7片军叶综刺接种 & 7 & 4 & - & - & 4.85 & 67.96 & 65.05 \\
\hline 对 照 & - & -1 & 一 & $一$ & $\longrightarrow$ & 一 & 一 \\
\hline
\end{tabular}

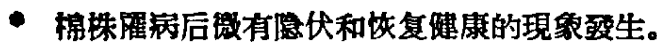

試驗証明，当环境条件适合时（主要是温度），棉 株虽在苗期（2-3 片资叶）亦能發生黃萎病，而潜育 期的长短，件随环境条件的轉变而轉变。一般在伤口 侵入的情况下，潜育期通常为 8-14 天。但至 6-7 片 员叶以后，因温度逐激升高而發病也最快。潜育期可 樎短为 3 天（黃萎适宜温度一般为 $22-24^{\circ} \mathrm{C}$ )。而士 壤接种的处理, 多在接种的 1-2个月內才开始大量
病，而罯病的棉株也为数懒少。

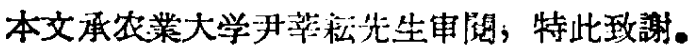
耿 殿 棨

(东北农業科学的究所辽陽棉作嚗)

1957 年 7 月 3 日

\section{白云鄂博区域地質简报}

白云鄂博区位于包头正北 145 公里。該区主要是

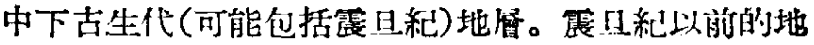

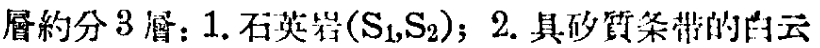

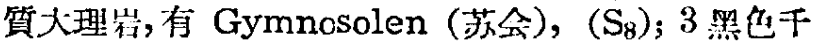
枚岩、石英岩、变質灰岩等互恰 $\left(\mathrm{S}_{3}\right)$ 。此系地情很可

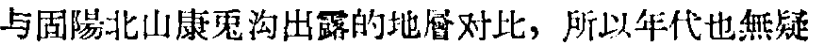

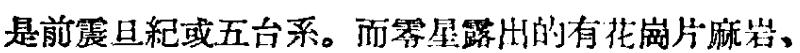
片麻岩、角閃片岩等, 他們可与除川所产的对比, 年 代当为桑干系或太古代。白云山脉主姴的地詹是: 1:石 英岩 $\left(\mathrm{S}_{4}\right)$, 可能盖有黑板岩和石英竹的互層 $\left(\mathrm{S}_{5}\right) ; 2$.

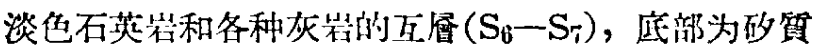
条带的白云質灰岩, 中上部为黑色䟚質灰岩, 越上越

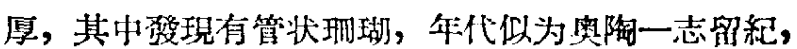
而石英岩只見于中下部，越上越少; 3. 細粒石英岩， 炭質石英岩和板岩的互層 $\left(\mathrm{S}_{9}\right)$ ，在有些地方跟線出片

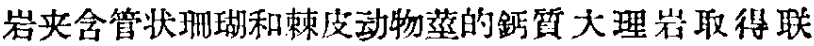
系, 所以此層的年代也似为奥陶一志留紀。这一大系 地居, 厚約几千公尺以上, 很像是游相地槽沉积, 可 惜沼有發現真正的寒武紀和奥隐紀的化不，所以对他 認識还不够完全。在泊云山脉北带有合很多化石的石

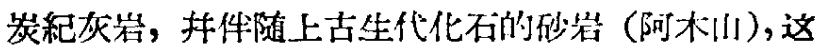
些真正的上古生代地層, 不但不厚, 抹且汥有变啠, 而灰岩的稍微变質只能涗明遭受动力作用，因为找不 着跟花風岩的关系。在这化带的南部, 还有一些砂岩 夹砾岩，或綠或紅，未找着化石，植物碎㕍不易愁定， 所以他的年代，可能是上古生代或中生代，但决不是 新生代。在此区域成片的新生代地畨非常少見，因此 就不多叙。

关于岩浆活动, 主要的有两期: 前霞旦紀和中下 古生代。在前震旦紀, 主要是粒状花崗岩, 在隐川非: 常常見，在白云山脉中，常遭挤压，件随其他地恬，

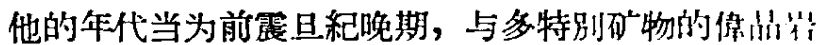
似有血緣的关系。另有片麻岩化的花南紧，在险川非 常常見, 似为最老的花崗岩 (太古生?)，在白云山川 只成断塊而已。在中下古生代，有很大的嗔㹲安川栄 系，噴發时期似与緗色片岩很接近，也有很大的超焦 性岩侵入，現已蛇紋岩化，而浩成鉄矿的热液毫無疑 义地是它带来的，因为矿化的白云質大理岩、蛇紋 